\title{
A Software for Optimizing the Thermal Power Plant Operation under Environmental Constraints
}

\author{
Chunxiu Zhang \\ North China Electric Power University, Baoding 071003, China \\ 1597629272@qq.com
}

\begin{abstract}
Keywords: Environmental costs, Cost of electricity, Optimal operation of thermal power system, Data Mining
\end{abstract}

\begin{abstract}
On the basis of the historical data of unit operation, consider the environmental cost, and KWH cost into the evaluation system, in order to developing guiding optimal operation of the thermal power units to run the software optimization. Through correlation analysis of the unit operation parameters, to determine regulatory indicators; Excavation and screening of historical data from the plant database, find out under the same load and sulfur content of the related parameters of the optimum operation condition, fully consider the thermal control system and optimization results, the matching relation between proposed operation parameters for the operation personnel adjustment unit to make it close to the optimization results, make recommendations for operational staff to adjust operating parameters of the unit to make running closer to optimal results, which can helps guiding the crew's running and reducing the unit's emissions to increase economic efficiency.
\end{abstract}

\section{Introduction}

The development takes existing environmental costs of thermal power ender optimal operation into account,aimed at on the basis of existing thermal power unit operation data,brings the the environmental costs into the evaluation system of thermal power plants, introduces the KWH cost to establish a evaluation system consideration the economic benefits of the power supply coal consumption and the environmental cost of coal-fired power plant evaluation system to guide the coal-fired power plant in running under the premise of meet the national standards, so as to improve economic benefit.

\section{Design}

Principle.

In KWH cost to analyze the efficiency of coal-fired power plant desulfurization system, KWH cost includes: unit capacity of the equipment cost and maintenance cost (f), the unit power supply of fuel costs (cf), unit power supply material consumptions cost (cw), unit power loss cost (ce). Formula is as follows: $c=f+c f+c w+c e$ (1)

And $f$ not reference, so we only consider the $\mathrm{cf}$ in economic analysis, the cw, ce. Formula is as follows: $c=c f+c w+c e$

Calculation of economic performance indicators.

First, Coal cost calculation of the power plant:

$$
c f=\frac{M}{P} \times 800 \div 10000
$$

Second,Material consumptions of the desulfurization system in power cost calculation: from three aspects: pulping system, absorption system and gypsum dewatering system, limestone consumption, water consumption and gypsum output . 
Since the amount of fuel in the production of content and desulfurization system are approximately equal, it can be obtained by conversion to coal of total sulfur S\%: $\mathrm{S} \%=S d \div M \div 0.8 \div 2 \div 1000 \times \frac{21 \%-O \%}{21 \%-6 \%} \times V$

Removal amount $(\mathrm{kg} / \mathrm{h})$ : $\mathrm{Mso} 2=(S d-S c) \times V \div 100000$

The required amount of limestone $(\mathrm{kg} / \mathrm{h})$ :

$$
\text { Mli }=\frac{M s o 2}{64.06} \times 1.02 \times 100.09 \times 100 \div 0.9605 \times 1.03 \div \frac{100-2}{100}
$$

Limestone required expenditure: $P l i=M l i \times 60 \div 1000$

Gypsum Yield (kg / h): Mgy = Mli $\times 1.7$

Gypsum Income: $P g y=M g y \times 30 \div 1000$

The required amount of water: water expenditure: $M w=0.026 \times M l i \times 0.7 \div(0.3-0.026) \div 0.026 \times(1-0.026)+0.026 \times M l i \times 0.7 \div(0.3-0.026)(10)$

In summary, the material consumption cost calculation of power plant desulfurization unit power supply system are: $\mathrm{cw}=(p l i+p w-p g y) \div P \div 10000$

Third, Environmental damage cost of thermal power plant emissions are calculated as follows: Referencing 《State Council issued a comprehensive energy reduction program of work notice》, which shows excessive sulfur dioxide emission fee is 1.26 yuan / kg.

Environmental damage cost unit power supply unit as follows:

ce $=(S c-200) \times V \div 1000000 \times 1.26 \div P \div 10000$

To sum up, the KWH cost is: $\mathrm{c}=\mathrm{cf}+\mathrm{cW}+\mathrm{ce}$

NOTE: $M$ is the quantity of fuel, t; P net generating capacity, ten thousand kw; standard coal unit price to 800 yuan / tons; s\% sulfur coal-fired; V dry flue gas standard, ten thousand,m3/h ; Sc is net flue gas sulfur Sc,mg/nm3; limestone content of $\mathrm{Li} \%=96.05 \%$ count; calcium sulfur ratio, 1.03; slurry loss rate 2; the price of water for industrial use according to Jiujiang of Jiangxi price 1.66 yuan / tons.

\section{Software System Profile}

\section{Brief introduction.}

According to the running efficiency calculation model designed a "thermal power system operation optimization guidance" . Software on the history of the power plant operation data, data mining based on historical operating conditions the optimal parameters of guide future optimization operation of the similar conditions.

Software uses C/S structure, the compiler generates under VS2008, compatible with WinXp/Vista / 7/8 and other mainstream Windows operating system. The sample database using SQL2008, accord with standard of the ODBC data source, in the case of without secondary development can and power plants run most of the DCS, SIS system seamless docking. The core algorithm in the form of DLL encapsulation, provides a good secondary development interface, also facilitate the core algorithm of updating.

After starting software, the operator only need to input the unit operation parameters such as load, and coal sulfur content, the software can automatically search matching condition from the historical data of the optimal operation parameters, on the graphical interface intuitive feedback to the operator. After setting DCS access can will run a key parameter to import DCS system, the control unit operation, friendly interface, simple operation.

\section{Design Architecture}

Software data is based on database storage unit operation parameters. First of all set up and the database connection, get the latest operation of the unit data, including load, coal, coal industrial composition, etc. Then according to the economic calculation model to calculate the cost of each set of operation parameters corresponding KWH. Then according to the KWH cost of screening a (load, 
the sulfur content of coal) to determine the conditions of the optimal operation condition, and the running parameters of storage to the local data files. In this way, the user input a set of parameters, program will input parameters and the matching of data in the local data files, and will be returned to the corresponding data terminal equipment, guide the parameter adjustment of operating personnel. In the case of open DCS interface, can communication through pipes will run into DCS parameter in a specific format automatic control operation.

\section{Software interface.}

Software interface can provide a real-time query data and determine the optimization target of a man-machine interactive interface. When the crew input unit operation load and sulfur content in the window, the page will show the parameters of the historical data under moderate electric cost minimum value corresponding to the point, as shown in figure, the red flag, and showed the corresponding optimization adjustment of parameter data. At the same time, you can update the data and real-time monitor button to update the data, keep the integrity of the data and database update.

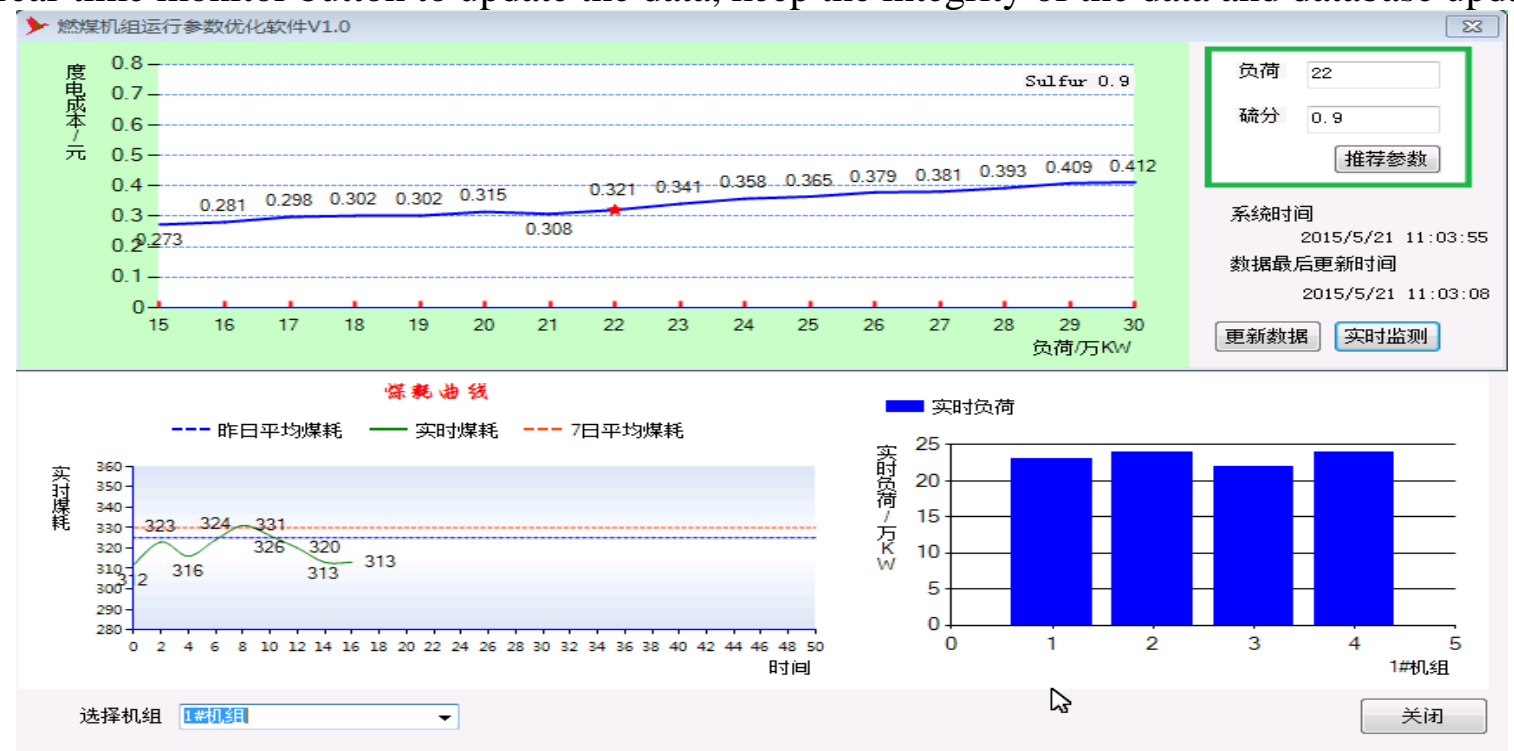

\section{Summary}

Study of thermal power unit operation optimization techniques, the environmental cost of the equipment operation should be brought into the assessment, to introduce the concept of degrees of electricity cost and establish a new evaluation system, the method of data mining is used to determine the thermal power unit operation optimization working point, the data updated in real time, the development environment under the constraint of thermal power unit operation optimization system, can realize energy conservation and emissions reduction, reduce KWH cost, improve the power efficiency, bid for coal-fired power plants on the Internet and provide powerful basis for sustainable development. The project in a large number of unit operation, on the basis of historical data, summarizes the key indicators of energy saving and operation optimization, at the same time provides an efficient optimization scheme for the operation staff, to improve the economic operation level of the unit and reduce the energy consumption of the unit is of great significance.

\section{References}

[1] Shi Qing. Optimization of thermal unit operation optimization system development and application of [D]. University of Electronic Science and Technology, 2012

[2] Liu Dianhai PROCEEDINGS, Yang Kun and other studies into account the environmental costs of thermal power unit power generation cost [J] China Power 2005 (09): 24-28.

[3] Yuan Stars study of large coal-fired unit wet flue gas desulfurization system to optimize the overall operation of [D]. North China Electric Power University .2012. 
[4] Bob power plant Limestone - gypsum wet flue gas desulfurization system research [D] .2010 optimization Beijing Jiaotong University.

[5] Zhou Zufei run coal-fired power plant flue gas desulfurization system optimization. [J]. Zhejiang Electric Power Test and Research Institute (2008).

[6] Young Choi industry. Optimization of energy-saving technology small thermal power boiler [J]. Inner Mongolia Qinghua Group New Energy Power Co., Ltd. .2014. 